\title{
Immunogenicity of SARS-CoV-2 mRNA Vaccines in Patients with Cancer: Findings from an International Collaborative Cohort Study
}

\author{
Alfredo Addeo \\ University Hospital of Geneva \\ Pankil Shah \\ Mays Cancer Center at UT Health San Antonio MD Anderson \\ Natacha Bordry \\ University Hospital of Geneva \\ Robert Hudson \\ Mays Cancer Center at UT Health San Antonio MD Anderson \\ Brenna Albracht \\ Mays Cancer Center at UT Health San Antonio MD Anderson \\ Mariagrazia Di Marco \\ University Hospital of Geneva

\section{Virginia Kaklamani} \\ University of Texas Health Science Center at San Antonio
}

\section{Pierre-Yves Dietrich}

University Hospital of Geneva

\section{Barbara Taylor}

Joe R. and Teresa Lozano Long School of Medicine, UT Health San Antonio

\section{Pierre-Francois Simand}

University Hospital of Geneva

\section{Darpan Patel}

Mays Cancer Center at UT Health San Antonio MD Anderson

Jing Wang

Mays Cancer Center at UT Health San Antonio MD Anderson

Inthidar Labidi-Galy

University Hospital of Geneva

Sara Fertani

University Hospital of Geneva

\section{Robin Leach}

Mays Cancer Center at UT Health San Antonio MD Anderson

Jose Sandoval

University Hospital of Geneva

Ruben Mesa

University of Texas Health Science Center at San Antonio

\section{Kate Lathrop}

Mays Cancer Center at UT Health San Antonio MD Anderson

Nicolas Mach

University Hospital of Geneva

Dimpy Shah ( $\square$ shahdp@uthscsa.edu )

Loading [MathJax]/jax/output/CommonHTML/jax.js pnio MD Anderson https://orcid.org/0000-0001-9019-8310 


\section{Article}

Keywords: COVID-19, immune response, malignancy, tumor, pandemic, seroconversion, antibody, oncology

Posted Date: May 24th, 2021

DOl: https://doi.org/10.21203/rs.3.rs-554993/v1

License: (c) (i) This work is licensed under a Creative Commons Attribution 4.0 International License. Read Full License 


\section{Abstract}

Patients with cancer experience higher burden of SARS-CoV-2 infection, disease severity, complications, and mortality, compared to the general population. SARS-CoV-2 mRNA vaccines have shown to be highly effective in clinical trials; however, few data are available on the efficacy of SARS-CoV-2 vaccines in patients with cancer. Using a prospective cohort study design, we assessed the seroconversion rates and anti-SARS-CoV-2 S antibody titers following the 1st and 2nd dose of BNT162b2 and mRNA-1273 SARS-CoV-2 vaccines in patients with cancer at centers in U.S. and Europe from January 2021 to April 2021. Among 131 patients included in the immunogenicity analysis, most (94\%) developed antibody levels; however, $6 \%$ showed no seroconversion after completing the mRNA vaccination series. No differences in seroconversion rates were observed between BNT162b2 and mRNA1273 vaccine groups. Patients with solid tumors (98\%) were much more likely to seroconvert and develop higher antibody titers than those with hematological malignancy $(77 \%)$. Although seroconversion rates were consistently high in patients receiving different types of anti-cancer therapy except anti-CD-20 antibody; the antibody titers were much lower in patients who received cytotoxic chemotherapy, immunotherapy, or monoclonal antibody compared to those on clinical surveillance or receiving endocrine therapy within six months prior to vaccination. None of the patients on anti-CD-20 antibody therapy developed an antibody response, even after receiving 2 doses of the vaccines. After correlating with cell-mediated immunity in a subset of patients at high-risk for antibody non-response, we propose exploring the addition of a second booster, or convalescent plasma therapy, or postpone vaccination until after completion of their specific anti-cancer treatment. Although encouraging results, we suggest high-risk vaccinated patients with cancer to continue taking safety precautions until their immune response is confirmed at 4 weeks after 2 nd dose of mRNA vaccines. We also highly encourage all eligible individuals in the general population to get vaccinated to ensure the protection of the most vulnerable groups, such as those with cancer.

\section{Introduction}

The novel coronavirus disease 2019 (COVID-19) pandemic has spread throughout the world with over 161 million confirmed cases globally and more than 3 million deaths as of May 2021. ${ }^{1}$ Unprecedented global effort has been made to develop different SARS-CoV-2 vaccines using technologies based on messenger RNA (mRNA), synthetic long viral peptides, plasmid DNA, and inactivated, attenuated, or genetically modified viruses including those from Pfizer-BioNTech, ${ }^{2}$ Moderna, ${ }^{3}$ Oxford-AstraZeneca, ${ }^{4}$ and Johnson \& Jonhson. ${ }^{5}$ Efficacy ranges between $60 \%$ and $94 \%$ with excellent safety profile in the general population. However, scarce experimental data about safety and efficacy of vaccine have been reported on patients with cancer, as they were excluded from SARS-CoV-2 vaccine clinical trials.

Patients with cancer have been heavily affected by the COVID-19 pandemic either by representing a more vulnerable population ${ }^{6}$ or by the disruption of their care pathway caused by the pandemic. ${ }^{7}$ Most healthcare settings implemented minimal services with programmed activity being canceled or suspended, and patients have delayed routine health procedures or assessment of serious symptoms, due to fear of visiting providers that were also handling suspected COVID-19 cases. It has been estimated that about $40 \%$ of countries reported partial or complete disruptions of cancer treatment during the different peaks of the pandemic. ${ }^{8}$

Compared to the general population, patients with cancer are more likely to be at high risk of serious COVID-19-related complications and mortality, 6,9 hence having information about efficacy of vaccine and optimal timing in relation to anti-cancer therapy to promote an effective immunity in this population remains crucial.

Here, we report the first results from an international collaborative prospective cohort study assessing short-term humoral immune response (seroconversion rates and antibody titers) after 2 doses of mRNA vaccines (mRNA-1273 or BNT162b2) in 2 different cohorts of patients with solid and hematological malignancies. To put our study findings in the context of the existing literature, we also present data from available studies (published or pre-print) examining anti-SARS-CoV-2 Spike IgG antibody response rates in patients with cancer who received SARS-CoV-2 vaccines.

\section{Methods}

\section{Sturlv decinn}

Loading [MathJax]/jax/output/CommonHTML/jax.js 
We performed a prospective observational cohort study on patients with cancer who received mRNA-1273 or BNT162b2 vaccine at University Hospital of Geneva (HUG) or Mays Cancer Center at University of Texas Health San Antonio MD Anderson (MCC) between January 29, 2021, and April 24, 2021. Vaccination series was administered as per the manufacturer guidelines (gap between 1st and 2nd dose was 21 days for mRNA-1273 and 28 days for BNT162b2). Participants were enrolled in the study by signing an informed consent. This study was approved by institutional review boards at each institution.

\section{Inclusion / Exclusion Criteria}

The inclusion criteria consisted of adult patients (age 18 years or older), eligible to receive COVID-19 vaccination, diagnosed with any malignancy with the exception of early-stage squamous cell skin cancer, early-stage basal cell skin carcinoma and noninvasive pathology such as Ductal Carcinoma in-situ (DCIS). Patients who were currently receiving anti-cancer treatment or had received active treatment within the last 5 years, were eligible. Exclusion criteria included a laboratory confirmed diagnosis of SARS-CoV-2 exposure either by polymerase chain reaction or serology, previous enrollment in a COVID-19 vaccine trial, pregnancy or breastfeeding, and unable to comply with study-related procedures.

\section{Procedures}

Blood samples are collected at the time of the first vaccination (baseline), at the time of the second dose (timepoint 1) and at day 50 after the first dose (timepoint 2), day 90, 180, and 365 after their first dose. Here, we are reporting on all available serum samples from baseline, timepoint 1, and timepoint 2. These samples were tested for both anti-SARS-CoV-2 Spike IgG and Nucleocapsid IgG titers. Follow-up analysis is planned to investigate long-term immunogenicity of mRNA vaccines.

\section{Anti-SARS-CoV-2 Spike IgG and Nucleocapsid IgG assays}

The immunogenicity of mRNA vaccines was assessed for antibody seroconversion by ELISA. As previously reported (Andrey et al., Eur J Clin Invest 2020; Stringhini et al., Lancet, 2020), we used the Euroimmun IgG enzyme-linked immunosorbent assays (ELISA) (Euroimmun AG, Lübeck, Germany \# El 2606-9601 G; CE-marked) to assess SARS-CoV-2 IgG serology against the S1domain of the Spike protein (anti-S1 lgG) and the Nucleocapsid Protein (anti-N-IgG). EDTA serum were analyzed according to the manufacturer's instructions. Results of patient sample's immunoreactivity are expressed as the ratio of the optical density at 450 $\mathrm{nm}$ (OD450) divided by the calibrator's OD450. The ratio is interpreted as follows: OD450 ratio: $<0.8$ is negative; $\geq 0.8$ and $<1.1$ is indeterminate; and $\geq 1.1$ is positive for $\operatorname{lgG}$ anti-S, while $>1.0$ is positive for $\lg \mathrm{G}$ anti-N and $\leq 1.0$ is negative.

\section{Outcomes}

The current study has two primary outcomes: 1) rates of seroconversion to the SARS-CoV-2 S protein; and 2) anti-SARS-CoV-2 S antibody titer levels in patients with cancer following 1st and 2nd dose of vaccination with BNT162b2 or mRNA-1273.

\section{Statistical analysis}

All patients with available samples and data were included in the immunogenicity

analyses. After preliminary examination for data accuracy and integrity, patients having previous SARS-CoV-2 exposure based on anti-SARS-CoV-2 $\mathrm{N}$ or S antibody test at enrollment were excluded from immunogenicity analysis. We present the antibody response to vaccination in this subset of patients with prior SARS-CoV-2 exposure, separately. In the remaining cohort of eligible patients, we assessed seroconversion rates (number of patients with positive anti-SARS-CoV-2-S divided by the number of patients assessed) for timepoints 1 (post 1 st vaccine dose) and 2 (post 2 nd vaccine dose). The seroconversion rates were stratified by age, sex, race/ethnicity, vaccine type, cancer type, and anti-cancer treatment modality. We also calculated overall and stratified median and interquartile range of anti-S antibody titer. Boxplot-overlaid-Violin plots were drawn to display the frequency and distribution of seroconversion rates and anti-S titers for each group. To improve reproducibility between vaccine serology studies, null hypothesis significance testing was not performed for this descriptive cohort study analysis. Statistics were computed in R, version 4.0.4 ( $\mathrm{R}$ Core Team 2020).

\section{Results}

Loading [MathJax]/jax/output/CommonHTML/jax.js 
We enrolled a total of 140 patients with cancer who received either BNT162b2 or mRNA-1273 vaccine at one of the enrolling sites. Among these patients, 131 were SARS-CoV-2 naïve, and thus included in the immunogenicity analysis (Table 1) with a median follow-up of 50 (range: 49-55) days from their first vaccine dose. The median (interquartile range, IQR) age at vaccination was 63 (55-69) years and the racial/ethnic distribution of patients was representative of our centers' demographic composition: NonHispanic White (80\%) Hispanic (18\%), and Black (2\%). There was almost equal proportion of males (55\%) and females (45\%) at both sites. Most malignancies were solid tumors (81\%), with breast (33\%) and urological (19\%) cancer being the most common solid tumor types. Twenty-five (19\%) patients had hematological malignancy. Approximately, one-third did not receive anti-cancer therapy within 6 months prior to COVD-19 vaccination. The most common anti-cancer therapy received by this cohort of patients was cytotoxic chemotherapy (23\%), followed by endocrine (15\%), monoclonal antibody (13\%), kinase inhibitors (11\%), and immunotherapy (11\%). 


\begin{tabular}{|c|c|}
\hline $\mathbf{N}$ & 131 \\
\hline Age, years, median (IQR) & $63(55-69)$ \\
\hline \multicolumn{2}{|l|}{ Sex } \\
\hline Male & $72(55)$ \\
\hline Female & $59(45)$ \\
\hline \multicolumn{2}{|l|}{ Race } \\
\hline Non-Hispanic White & $105(80)$ \\
\hline Hispanic & $23(18)$ \\
\hline Black & $3(2)$ \\
\hline \multicolumn{2}{|l|}{ Type of Malignancy } \\
\hline Solid Malignancies & $106(81)$ \\
\hline Breast & 27 \\
\hline Urological & 20 \\
\hline Gynecological & 3 \\
\hline Skin cancers $^{+}$ & 7 \\
\hline Thoracic malignancy & 18 \\
\hline Gastrointestinal & 16 \\
\hline Head and neck cancer & 3 \\
\hline Brain & 8 \\
\hline Connective tissue & 4 \\
\hline Haematological malignancies & $25(19)$ \\
\hline Acute lymphoblastic leukemia (ALL) & 1 \\
\hline Chronic myeloid leukemia (CML) & 1 \\
\hline Chronic lymphocytic leukemia (CLL) & 1 \\
\hline Diffuse large B cell lymphoma & 6 \\
\hline Follicular lymphoma & 2 \\
\hline MALT lymphoma & 2 \\
\hline T-cell Lymphoma/Mycosis Fungoides & 2 \\
\hline Hodgkin's lymphoma & 4 \\
\hline Polycythemia Vera & 1 \\
\hline Myeloma & 5 \\
\hline
\end{tabular}

+6 melanoma, 1 Merkel cell

*12 patients received more than 1 anti-cancer treatment 


\begin{tabular}{|ll|}
\hline N & 131 \\
\hline Type of anti-cancer treatment* (within 6 months of vaccination) & $49(37)$ \\
\hline Clinical surveillance & $30(23)$ \\
\hline Cytotoxic chemotherapy & $14(11)$ \\
\hline Immunotherapy & $19(15)$ \\
\hline Endocrine therapy & $4(3)$ \\
\hline Anti-CD-20 antibody & $1(1)$ \\
\hline Anti-CD-38 antibody & $2(2)$ \\
\hline Anti-HER antibody & $6(5)$ \\
\hline Anti-VEGF antibody & $4(3)$ \\
\hline RANKL antibody & $15(11)$ \\
\hline Kinase Inhibitor & $1(1)$ \\
\hline Unknown** & \\
\hline SARS-CoV-2 Vaccine & $38(29)$ \\
\hline BNT162b2 & $93(71)$ \\
\hline mRNA-1273 & $50(49-55)$ \\
\hline Time between first vaccine dose and final outcome measurement, days, median (range) & \\
\hline+6 melanoma, 1 Merkel cell & \\
\hline$* 12$ patients received more than 1 anti-cancer treatment & \\
\hline$* \star$ patient enrolled in a double-blinded placebo-controlled trial & \\
\hline
\end{tabular}

\section{Serological Outcomes}

Overall, a high rate of seroconversion (anti-S IgG) (94\%) was observed in our cohort of patients with cancer who received complete mRNA vaccination series (Table 2). Consistently, the seroconversion rates and antibody titers were lower after the $1 \mathrm{st}$ vaccine dose and preferred outcomes were attained after receipt of the 2nd dose in all subgroups (Fig. 1). The seroconversion rates and antibody titers were similar between BNT162b2 and mRNA-1273 vaccines (Supplementary Fig. 1). We did not observe any differences in outcomes by age or sex. There was a signal for lower seroconversion rate in Black patients (67\%) compared to Non-Hispanic White patients (94\%); however, numbers were too small for detailed analysis or inference. 
Serological outcomes following SARS-CoV-2 mRNA Vaccines

\begin{tabular}{|c|c|c|c|c|}
\hline & \multicolumn{2}{|c|}{ Post 1 st vaccine dose } & \multicolumn{2}{|c|}{ Post 2nd vaccine dose } \\
\hline & $\begin{array}{l}\text { Positive, } \\
\text { n (\%) }\end{array}$ & Titer $(\mathrm{U} / \mathrm{mL})$, median $(\mathrm{IQR})$ & $\begin{array}{l}\text { Positive, } \\
\text { n (\%) }\end{array}$ & Titer $(\mathrm{U} / \mathrm{mL})$, median (IQR) \\
\hline Overall & $98 / 121(81 \%)$ & $32(2-105)$ & $116 / 123(94 \%)$ & $2501(438-2501)$ \\
\hline \multicolumn{5}{|l|}{ mRNA Vaccine } \\
\hline Pfizer BNT162b2 & $24 / 29(83 \%)$ & $29(2-103)$ & $28 / 30(93 \%)$ & $1232(258-2501)$ \\
\hline Moderna mRNA-1273 & $74 / 92(80 \%)$ & $34(3-106)$ & $88 / 93(95 \%)$ & $2501(442-2501)$ \\
\hline \multicolumn{5}{|l|}{ Age, years } \\
\hline Younger than 65 & $54 / 64(84 \%)$ & $34(3-118)$ & $64 / 66(97 \%)$ & $2501(506-2501)$ \\
\hline 65 and older & $44 / 57(77 \%)$ & $31(1-96)$ & $52 / 57(91 \%)$ & $2177(401-2501)$ \\
\hline \multicolumn{5}{|l|}{ Sex } \\
\hline Male & $53 / 69(77 \%)$ & $18(1-74)$ & $64 / 69(93 \%)$ & $1762(364-2501)$ \\
\hline Female & $45 / 52(87 \%)$ & $44(8-148)$ & $52 / 54(96 \%)$ & $2501(840-2501)$ \\
\hline \multicolumn{5}{|l|}{ Race/Ethnicity } \\
\hline $\mathrm{NHW}$ & $79 / 100(79 \%)$ & $32(2-106)$ & $96 / 102(94 \%)$ & $2501(438-2501)$ \\
\hline Hispanic & 18/19 (95\%) & $32(5-125)$ & 18/18 (100\%) & $2396(755-2501)$ \\
\hline Black & $1 / 2(50 \%)$ & $29(15-44)$ & $2 / 3(67 \%)$ & $1770(885-2136)$ \\
\hline \multicolumn{5}{|l|}{ Type of malignancy } \\
\hline Solid tumor & $80 / 96(83 \%)$ & $44(4-137)$ & 99/101 (98\%) & $2501(514-2501)$ \\
\hline Haematological malignancy & $18 / 25(72 \%)$ & $6(0-33)$ & $17 / 22(77 \%)$ & $832(24-2501)$ \\
\hline \multicolumn{5}{|l|}{ Anti-Cancer Therapy } \\
\hline Clinical surveillance & $38 / 44(86 \%)$ & $60(5-185)$ & $44 / 45(98 \%)$ & 2501 (934-2501) \\
\hline Cytotoxic & $20 / 29(69 \%)$ & $4(0-18)$ & $28 / 30(93 \%)$ & $611(160-1956)$ \\
\hline Immunotherapy & 11/13 (85\%) & $21(4-43)$ & $13 / 14(93 \%)$ & $1116(627-2501)$ \\
\hline Endocrine therapy & 15/16 (94\%) & $66(30-137)$ & 18/18 (100\% & $2501(2501-2501)$ \\
\hline Anti-CD-20 antibody & $0 / 4(0 \%)$ & $<0.4$ & $0 / 4(0 \%)$ & $<0.4$ \\
\hline Anti-CD-38 antibody & $1 / 1(100 \%)$ & 1 & $1 / 1(100 \%)$ & 203 \\
\hline Anti-HER antibody & $2 / 2(100 \%)$ & $18(11-25)$ & $1 / 1(100 \%)$ & 2501 \\
\hline Anti-VEGF antibody & $4 / 5(80 \%)$ & $3(1-77)$ & $5 / 5(100 \%)$ & $329(82-2501)$ \\
\hline RANKL antibody & $3 / 4(75 \%)$ & $35(21-64)$ & $3 / 3(100 \%)$ & $2501(1301-2501)$ \\
\hline Kinase Inhibitor & $13 / 15(87 \%)$ & $51(6-78)$ & $12 / 13(92 \%)$ & $2501(439-2501)$ \\
\hline
\end{tabular}

Both the seroconversion rates and antibody titers were lower in patients with hematological malignancy compared to those with solid tumors (77\% vs 98\%) and (median, IQR: 832 [24-2501] vs > 2500 [514-2501]), respectively (Fig. 2). Antibody response was widely different between the various anti-cancer treatment modalities (Fig. 3). Patients receiving no therapy (i.e., clinical Loading [MathJax]/jax/output/CommonHTML/jax.js est outcomes with high seroconversion rates (98-100\%) and excellent median 
antibody titer $(>2500 \mathrm{U} / \mathrm{mL})$ after completing vaccination series. Although seroconversion rates were consistently high with most treatment modalities, lower level of antibody titer was observed for those who received cytotoxic chemotherapy (median, IQR: 611 [160-1956]), immunotherapy (1116 [627-2501]), and monoclonal antibody (152 [2-2501]), within 6 months prior to 1st vaccine dose (Table 2). None of the 4 patients receiving anti-CD-20 antibody showed seroconversion.

None of the patients on the study had IgG $\mathrm{N}$ while on study, so no breakthrough SARS-CoV-2 infections during the time from first dose of the vaccine to 1 month after 2 nd dose were noted in this study cohort.

\section{No Antibody Response after 2 vaccine doses}

A total of 7 patients (6\%) did not develop any antibodies after completing 2 doses of mRNA vaccines. All of these patients were older (more than 55 years), majority were males (5/7 [71\%]), and non-Hispanic White (6/7 [86\%]). A disproportionately higher proportion of the patients with no antibody response had hematological malignancy (5/7 [71\%]), including 2 Diffuse Large B Cell Lymphoma, 1 MALT Lymphoma,1 Follicular lymphoma, and 1 Hodgkin's Lymphoma. The other 2 malignancies were adenocarcinoma of the colon and squamous carcinoma of the lung, both of these patients had metastasis to liver. All but 1 patient (6/7 [86\%]) with non-response to vaccines were on active anti-cancer treatment within 6 months prior to the vaccination. Rituximab (57\%) was the most common anti-cancer drug in this group. Other drugs included Folfox (Leucovorin, 5-Fluorouracil, Oxaliplatin), Pembrolizumab, Ibrutinib, and radiotherapy.

\section{Antibody Response in Patients with Prior SARS-CoV-2 Exposure}

Of the 9 patients with SARS-CoV-2 infection prior to receiving vaccination, baseline anti-S titer was low (132 [55-389]) but showed robust response after 1 st dose (2238 [696-2501]) and 2nd dose was (2501 [1376-2501]).

\section{Discussion}

We present the first results of an international collaborative prospective cohort study between 2 premiere cancer centers in U.S. and Switzerland assessing the humoral immune response in patients with solid and hematological malignancies who received mRNA vaccines. Although the seroconversion rates were low at 3 to 4 weeks after 1 st dose; the seroconversion rate was consistently high (94\%) in the overall cohort at 4 weeks after receiving the 2 nd dose of the vaccine. A subset of patients (e.g., those older than 55 years, with hematological malignancy, metastatic solid malignancy, receiving active anti-cancer treatment, anti-CD-20 antibody) did not develop antibody response even after receiving 2 doses. In a small subset of patients with previous SARS-CoV-2 exposure, we also noted an increase in anti-S IgG antibody level from pre-vaccination to post-vaccination.

Given the high pressure posed by the pandemic and by evidence that patients with cancers are highly vulnerable to COVID-19,6,10 widespread vaccination campaign of patients with cancer has quickly taken off across the globe. ${ }^{11}$ While this strategy should be praised and promoted, little is known on the efficacy of vaccines in patients with cancer and about the impact that their anticancer treatments might have on the vaccine efficacy. Limited data on level of seroconversion in patients with cancer following COVID-19 vaccination is summarized in Table 3. Notably the anti-S IgG seroconversion rates were lower or less pronounced in patients with a hematological conditions, in particular in patients treated with highly immune suppressive therapy, such as stem cell transplantation, anti-CD20 therapy or chimeric antigen receptor (CAR)-T cell therapy. ${ }^{12}$ Small cohort studies have reported low seroconversion rates following a single dose of mRNA vaccination in the UK and France and seropositivity rates in patients with CLL and multiple myeloma. ${ }^{13,14}$ Within our cohort of 131 patients, the overall seropositivity rate was $81 \%$ after the first dose and up to $94 \%$ at 4 weeks after the second dose. No major difference between the 2 vaccines were noted in terms of percent positive response. However, the seroconversion rate was numerically lower in patients with hematological malignancy, $72 \%$ after the first dose an up to $77 \%$ after the second dose on day 50 . None of the patients receiving anti-CD-20 therapy $(0 \%, 4 / 4)$ produced any anti-S IgG antibodies despite receiving 2 doses of vaccine. Other treatment including chemotherapy, endocrine therapy, or immunotherapy (immune checkpoint inhibitors) had no discernable impact on the seropositivity rate, with a seroconversion rate estimated to $90 \%$ by day 50 . As previously showed in other studies, to properly appreciate seroconversion rate, the timing of

sampling is essential. ${ }^{13-16}$ Testing for antibody levels at 3 weeks after only the first dose of vaccine might provide partial information, making it difficult to interpret or infer vaccine efficacy. On the contrary, waiting two weeks after the 2 nd dose, as we

Loading [MathJax]/jax/output/CommonHTML/jax.js 
did in our study, could provide more reliable information on the seroconversion rate and antibody titer level, thus offering a more comprehensive picture.

Table 3

Studies on post-vaccination seroconversion in patients with solid or hematological cancer

\begin{tabular}{|c|c|c|c|c|c|c|c|c|}
\hline Study & Country & $\begin{array}{l}\text { Cancer } \\
\text { ype }\end{array}$ & $\begin{array}{l}\text { Number } \\
\text { of } \\
\text { patients } \\
\text { assessed } \\
\text { for each } \\
\text { timepoint }\end{array}$ & Vaccine & Dose & $\begin{array}{l}\text { Time } \\
\text { between 1st } \\
\text { vaccine dose } \\
\text { and antibody } \\
\text { measurement }\end{array}$ & $\begin{array}{l}\text { Antibody } \\
\text { test }\end{array}$ & $\begin{array}{l}\text { Seroconversion } \\
\text { (number of } \\
\text { patients, [\%]) }\end{array}$ \\
\hline $\begin{array}{l}\text { Palich et } \\
\mathrm{al}^{16}\end{array}$ & France & $\begin{array}{l}\text { Solid } \\
\text { cancer }\end{array}$ & 95 & BNT162b2 & 1 & 21 & Abbott & $52(55 \%)$ \\
\hline \multirow{2}{*}{$\begin{array}{l}\text { Monin et } \\
\mathrm{al}^{14}\end{array}$} & \multirow[t]{2}{*}{ UK } & \multirow[t]{2}{*}{ Both } & 100 & BNT162b2 & 1 & 21 & \multirow{2}{*}{$\begin{array}{l}\text { ELISA (in- } \\
\text { house) }\end{array}$} & 29 (29\%) \\
\hline & & & 24 & BNT162b2 & 2 & 35 & & 21 (87.5\%) \\
\hline $\begin{array}{l}\text { Herishanu } \\
\text { et } \mathrm{al}^{21}\end{array}$ & Israel & CLL & 167 & BNT162b2 & 2 & 21 & Elecsys & 66 (39.5\%) \\
\hline $\begin{array}{l}\text { Agha et } \\
\mathrm{al}^{22}\end{array}$ & USA & $\mathrm{HM}$ & 67 & $\begin{array}{l}\text { mRNA- } \\
1273 \\
\text { BNT162b2 }\end{array}$ & 2 & NA & $\begin{array}{l}\text { Beckman } \\
\text { counter }\end{array}$ & $31(46.3 \%)$ \\
\hline $\begin{array}{l}\text { Bird et } \\
\mathrm{al}^{15}\end{array}$ & UK & Myeloma & 93 & $\begin{array}{l}\text { BNT162b2 } \\
\text { AZD1222 }\end{array}$ & 1 & 21 & $\begin{array}{l}\text { Ortho } \\
\text { Clinical } \\
\text { Diagnostics } \\
\text { Total } \\
\text { antibody } \\
\text { test }\end{array}$ & 65 (70\%) \\
\hline $\begin{array}{l}\text { Terpos et } \\
\mathrm{al}^{23}\end{array}$ & Greece & Myeloma & 44 & BNT162b2 & 1 & 21 & $\begin{array}{l}\text { CPass }^{\mathrm{TM}} \\
\text { NAbs } \\
\text { Detection } \\
\text { Kit }\end{array}$ & $9(20.6 \%)$ \\
\hline \multirow[t]{2}{*}{ Barriere $^{13}$} & \multirow[t]{2}{*}{ France } & \multirow{2}{*}{$\begin{array}{l}\text { Solid } \\
\text { cancer }\end{array}$} & 122 & \multirow[t]{2}{*}{ BNT162b2 } & 1 & $21-28$ & \multirow[t]{2}{*}{ Elecsys } & 58 (47.5\%) \\
\hline & & & 42 & & 2 & $36-48$ & & 40 (95.2\%) \\
\hline \multirow{4}{*}{$\begin{array}{l}\text { Addeo } \\
\text { Shah et } \\
\text { al. } \\
\text { [Current } \\
\text { study] }\end{array}$} & \multirow{4}{*}{$\begin{array}{l}\text { Switzerland, } \\
\text { US }\end{array}$} & \multirow[t]{4}{*}{ Both } & 29 & \multirow[t]{2}{*}{ BNT162b2 } & 1 & 21 & \multirow[t]{4}{*}{ Elecsys } & $24(83 \%)$ \\
\hline & & & 30 & & 2 & 50 & & 28 (93\%) \\
\hline & & & 92 & \multirow{2}{*}{$\begin{array}{l}\text { mRNA- } \\
1273\end{array}$} & 1 & 28 & & $74(80 \%)$ \\
\hline & & & 93 & & 2 & 50 & & 88 (95\%) \\
\hline
\end{tabular}

Our data confirm the efficacy of the vaccine in triggering the humoral immune response in patients with cancer. On the other hand, it also reinforces the potential concern of inadequate protection in immunocompromised patients, especially those receiving anti-CD20 treatment, namely rituximab. There have been many publications highlighting the potential immunosuppressive activity of anti-CD20 therapy. Rituximab is a chimeric human-mouse monoclonal antibody used in the treatment of hematological malignancies and autoimmune diseases. ${ }^{17,18} \mathrm{It}$ reacts specifically with the CD20 antigen expressed on more than $95 \%$ of normal and malignant B-cells, inducing complement-mediated and antibody-dependent cellular cytotoxicity. Rituximab could indeed cause a rapid depletion of pre-B- and mature B-cells, which remain at low or undetectable levels for 2-6 months before returning to pretreatment levels, generally within 12 months. Growing evidence supports that rituximab might influence T- cell immunity as well. Rituximab may cause immunosuppression through several mechanisms such as delayed onset cytopenia, neutropenia in particular, if administered for long periods. It comes with no surprise that, in our study, patients receiving anti-CD-20 therapy did not develop any antibody titers for IgG-S. The optimal approach for vaccinating and monitoring this subset of patients at high-risk for non-response to SARS-CoV-2 vaccines remains unclear. Although a possible strategy might be to Loading [MathJax]/jax/output/CommonHTML/jax.js h as anti-CD-20 until after the 2 doses of vaccines have been administered, when 
possible, a more evidence-based strategy would be preferable. For instance, the health authority in France has issued a statement suggesting a third dose of vaccine, 3-4 weeks after the 2 nd dose in immunocompromised patients, but data on implementation and outcomes of adopting such a strategy have not been published as yet. Additionally, we observed that patients with prior SARS-CoV-2 exposure had low levels on anti-S antibody at baseline and showed a robust response after vaccination. Despite small numbers, this signals vaccination benefit in patients with history of COVID-19 and should be examined in a larger study.

The current study has several strengths including being the first international prospective cohort study of vaccinated patients with cancer, to date. We present data across diverse age groups, cancer types, cancer treatment types which is representative of patient population cared for at our cancer centers. It provides a comprehensive assessment of immunogenicity after 1 and 2 doses of SARS-CoV-2 mRNA vaccines in patients with solid and hematological malignancy. Secondly, our results are consistent, irrespective of the vaccine type and the patient characteristics across centers, and in line with existing literature on seropositivity rates in similar populations. A major strength of the study is the assessment of anti-N IgG at all the same pre-specified timepoints as anti-S IgG to ensure that no asymptomatic infection was overlooked. Further, to our knowledge, this is the first study to report response at day 50 after first vaccine dose, the longest duration of follow-up reported in vaccinated patients with malignancy.

Despite these strengths, there remain limitations due to the lack of corresponding data on cellular immunity for these patients. We acknowledge that this is an important component of the comprehensive examination of post-vaccine immune repertoire, so a cellmediated immune response analyses from this cohort are underway. A second potential limitation might be the utilization of antiS IgG assay as a surrogate for COVID-19 immunity in lieu of neutralizing antibodies; however, it is a reasonable scientific expectation that anti-Spike antibody titers would be highly correlated with neutralizing antibody activity. Thus, given its high sensitivity, specificity, agreement with other platforms, low cost and labor requirement, technical ease, and faster turn-around time, we chose anti-S IgG assay for this study, which can allow validation of these results in different population-based vaccine response studies ${ }^{19,20}$. Accurate surrogates for protection in the clinical setting remain to be established. Finally, due to our geographical location and time constraints, the cohort has inadequate representation of certain minority patients (e.g., Black, Asian, etc.), individual cancer types, and cancer treatments. We hope that this gap in knowledge would be addressed through a larger multi-national collaborative effort and will validate and expand on our study findings.

\section{Conclusions}

Our study documents that the vast majority of patients with cancer develop positive anti-SARS-CoV-2-Spike antibody response at 1-month post-completion of mRNA vaccination series, hence receiving both doses are recommended. A subset of patients showed no seroconversion despite receiving 2 doses of the vaccine. Various host factors such as underlying hematological malignancy, metastasis, and immunosuppressive anti-cancer treatments (e.g., anti-CD-20 antibody, cytotoxic chemotherapy) may impair humoral immune response to SARS-CoV-2 vaccines. Our results stress the importance of 1) Continued rapid and widescale vaccination of patients with cancer against COVID-19;2) Exploration of effective protection strategy (e.g., third dose of vaccine or convalescent plasma therapy) with consideration of timing of anti-cancer treatment for patients at high-risk for nonresponse to vaccines; 3 ) Continued safety precautions by vaccinated patients with cancer until confirmation of their immune response status; and 4) Reducing virus circulation in the general population by global vaccination efforts to protect most vulnerable groups, such as those with cancer.

\section{Declarations}

\section{Acknowledgements}

The Department of Oncology at Geneva University Hospitals would like to thank Sebastien Bugeia, Garance Gutknecht and Anna Battagin for their support with the enrollment and follow-up of participants. The authors would like to thank the University of Texas Health Biospecimen and Translational Genomics Core Laboratory for their support with the enrollment, processing of specimens and follow-up of participants at the MCC. We would also like to thank Brandon Wing, Nazneen Ali, and Adrian Tan for their health informatic support at the MCC.

Loading [MathJax]/jax/output/CommonHTML/jax.js 
Author Contributions: Drs. Addeo, P. Shah and D. Shah had full access to all the data in the study and take responsibility for the integrity of the data and the accuracy of the data analysis. Drs. Addeo and P. Shah contributed equally. Dr. Lathrop and Dr. D. Shah contributed equally.

Concept and design: Drs. Addeo, P. Shah, Kaklamani, Mesa, Leach, Lathrop, D. Shah.

Acquisition, analysis, or interpretation of data: Drs. Addeo, P. Shah, Hudson, Bordry, Mach, Fertani, Simmand, Di Marco, Dietrich, Albracht, Patel, Wang, Leach, Lathrop, D. Shah.

Drafting of the manuscript: Drs. Addeo, P. Shah, D. Shah.

Critical revision of the manuscript for important intellectual content: Drs. Addeo, Mach, Di Marco, Bordry, Dietrich, Simmand, Schuler, Sandoval, Fertani,P. Shah, Hudson, Albracht, Kaklamani, Taylor, Patel, Wang, Leach, Mesa, Lathrop, D. Shah.

Statistical analysis: Drs. P. Shah, D. Shah.

Obtained funding: Drs. Addeo, Mach, Dietrich Mesa, D. Shah.

Administrative, technical, or material support. Hudson, Albracht, Drs. Patel, Wang, Leach, Di Marco

Supervision: Drs. Addeo, Mach, P. Shah, Wang, Leach, Lathrop, D. Shah.

\section{Competing Interests statement}

Dr. Addeo reported receiving personal fees for attending advisory from Bristol-Myers Squibb, AstraZeneca, Roche, Pfizer, Merck Sharp and Dohme,Astella, Eli Lilly and Boehringer-Ingelheim. He has received fees for speaking bureau for Eli Lilly, AstraZeneca, MSD for work performed outside of the current study.

Dr. P. Shah reported receiving grant from the Biomedical Advanced Research and Development Authority outside of this work.

Dr Labidi-Galy reported receiving personal fees for attending advisory from AstraZeneca.

Proferssor Mach is a founder and minority shareholder of MaxiVAX SA, a private biotech company based in Geneva Switzerland, working on personalized cancer immunotherapy and infectious disease vaccines; with no impact on the current manuscript.

Dr. Taylor reported funding from NIAID/NIH and the COVID-19 Prevention Network which conducts COVID-19 vaccine trials.

Dr. Patel reported receiving grant support from the National Institutes of Health, Cancer Prevention Research Institute of Texas, ThriveWell Foundation and the Bill and Ella Owens Medical Foundation outside of this work

Dr. Wang reported receiving grants from 80/20 Foundation, National Institute of Health, and Nancy Smith Hurd Foundation.

Dr. Mesa reported receiving research support from Celgene, Incyte, Abbvie, Samus, Genotech, Promedior, and CTI; and consulting fees from Novartis, Sierra Onc, LaJolla, and Pharma.

Dr. D. Shah reported receiving grants from American Cancer Society and Hope Foundation for Cancer Research during the conduct of the study. Dr. D. Shah reported receiving grant from the Biomedical Advanced Research and Development Authority outside of this work. No other disclosures were reported.

All other coauthors reported no conflict of interests.

Funding: This project has been funded in whole or in part with federal funds from National Cancer Institute grant P30 CA054174 (Mays Cancer Center at University of Texas Health San Antonio MD Anderson); and grant MRSG-16-152-01-CCE the American Cancer Society and Hope Foundation for Cancer Research. A 'Research \& Development Program' grant from Geneva University Hospitals awarded to Natacha Bordry funded part of this study.

Loading [MathJax]/jax/output/CommonHTML/jax.js 
Role of the Funder/Sponsor: The funding sources had no role in the design and conduct of the study; collection, management, analysis, and interpretation of the data; preparation, review, or approval of the manuscript; and decision to submit the manuscript for publication.

\section{References}

1 https://covid19.who.int/.

2 Polack, F. P. et al. Safety and Efficacy of the BNT162b2 mRNA Covid-19 Vaccine. New England Journal of Medicine383, 2603-2615, doi:10.1056/NEJMoa2034577 (2020).

3 Baden, L. R. et al. Efficacy and Safety of the mRNA-1273 SARS-CoV-2 Vaccine. New England Journal of Medicine384, 403416, doi:10.1056/NEJMoa2035389 (2020).

4 Voysey, M. et al. Safety and efficacy of the ChAdOx1 nCoV-19 vaccine (AZD1222) against SARS-CoV-2: an interim analysis of four randomised controlled trials in Brazil, South Africa, and the UK. The Lancet397, 99-111, doi:10.1016/S01406736(20)32661-1 (2021).

5 Sadoff, J. et al. Safety and Efficacy of Single-Dose Ad26.COV2.S Vaccine against Covid-19. New England Journal of Medicine, doi:10.1056/NEJMoa2101544 (2021).

6 Kuderer, N. M. et al. Clinical impact of COVID-19 on patients with cancer (CCC19): a cohort study. The Lancet395, 19071918, doi:10.1016/S0140-6736(20)31187-9 (2020).

7 Riera, R. et al. Delays and Disruptions in Cancer Health Care Due to COVID-19 Pandemic: Systematic Review. JCO global oncology7, 311-323, doi:10.1200/go.20.00639 (2021).

8 Lai, A. G. et al. Estimated impact of the COVID-19 pandemic on cancer services and excess 1-year mortality in people with cancer and multimorbidity: near real-time data on cancer care, cancer deaths and a population-based cohort study. BMJ Open10, e043828, doi:10.1136/bmjopen-2020-043828 (2020).

9 Grivas, P. et al. Association of clinical factors and recent anticancer therapy with COVID-19 severity among patients with cancer: a report from the COVID-19 and Cancer Consortium. Annals of Oncology32, 787-800, doi:10.1016/j.annonc.2021.02.024 (2021).

10 Wang, Q., Berger, N. A. \& Xu, R. Analyses of Risk, Racial Disparity, and Outcomes Among US Patients With Cancer and COVID-19 Infection. JAMA Oncology7, 220-227, doi:10.1001/jamaoncol.2020.6178 (2021).

11 https://www.nytimes.com/interactive/2021/world/covid-vaccinations-tracker.html.

12 Thakkar, A. et al. Patterns of seroconversion for SARS-CoV-2 IgG in patients with malignant disease and association with anticancer therapy. Nature Cancer2, 392-399, doi:10.1038/s43018-021-00191-y (2021).

13 Barrière, J. et al. Impaired immunogenicity of BNT162b2 anti-SARS-CoV-2 vaccine in patients treated for solid tumors. Annals of oncology : official journal of the European Society for Medical Oncology, S0923-7534(0921)01183-01182, doi:10.1016/j.annonc.2021.04.019 (2021).

14 Monin-Aldama, L. et al. Interim results of the safety and immune-efficacy of 1 versus 2 doses of COVID-19 vaccine BNT162b2 for cancer patients in the context of the UK vaccine priority guidelines. medRxiv, 2021.2003.2017.21253131, doi:10.1101/2021.03.17.21253131 (2021).

15 Bird, S. et al. Response to first vaccination against SARS-CoV-2 in patients with multiple myeloma. The Lancet Haematology, doi:10.1016/S2352-3026(21)00110-1.

Loading [MathJax]/jax/output/CommonHTML/jax.js 
16 Palich, R. et al. Weak immunogenicity after a single dose of SARS-CoV-2 mRNA vaccine in treated cancer patients. Annals of Oncology, doi:https://doi.org/10.1016/j.annonc.2021.04.020 (2021).

17 https://www.ema.europa.eu/en/medicines/human/EPAR/mabthera.

1. https://www.accessdata.fda.gov/drugsatfda_docs/label/2012/103705s5367s5388lbl.pdf.

19 Mazzini, L. et al. Comparative analyses of SARS-CoV-2 binding ( $\operatorname{lgG}, \operatorname{lgM}, \lg A)$ and neutralizing antibodies from human serum samples. Journal of Immunological Methods 489, 112937, doi:https://doi.org/10.1016/j.jim.2020.112937 (2021).

20 Alvim, R. G. F. et al. An affordable anti-SARS-COV-2 spike protein ELISA test for early detection of IgG seroconversion suited for large-scale surveillance studies in low-income countries. medRxiv, 2020.2007.2013.20152884, doi:10.1101/2020.07.13.20152884 (2020).

21 Herishanu, Y. et al. Efficacy of the BNT162b2 mRNA COVID-19 Vaccine in Patients with Chronic Lymphocytic Leukemia. Blood, doi:10.1182/blood.2021011568 (2021).

22 Agha, M., Blake, M., Chilleo, C., Wells, A. \& Haidar, G. Suboptimal response to COVID-19 mRNA vaccines in hematologic malignancies patients. medRxiv, 2021.2004.2006.21254949, doi:10.1101/2021.04.06.21254949 (2021).

23 Terpos, E. et al. Low Neutralizing Antibody Responses Against SARS-CoV-2 in Elderly Myeloma Patients After the First BNT162b2 Vaccine Dose. Blood, doi:10.1182/blood.2021011904 (2021).

\section{Figures}




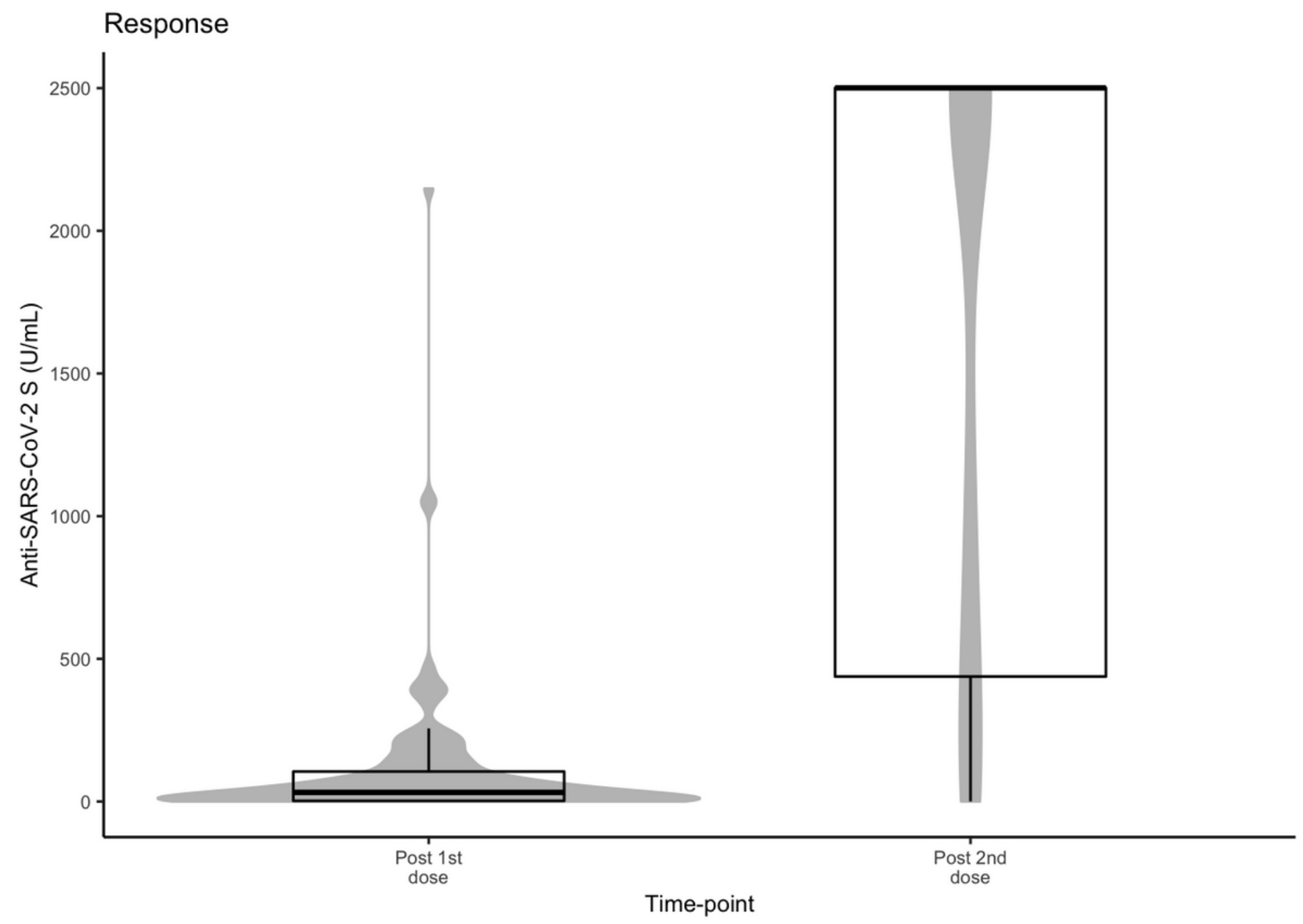

Figure 1

Anti-SARS-CoV-2 S IgG titers post 1 st dose and post 2 nd dose in the overall cohort 


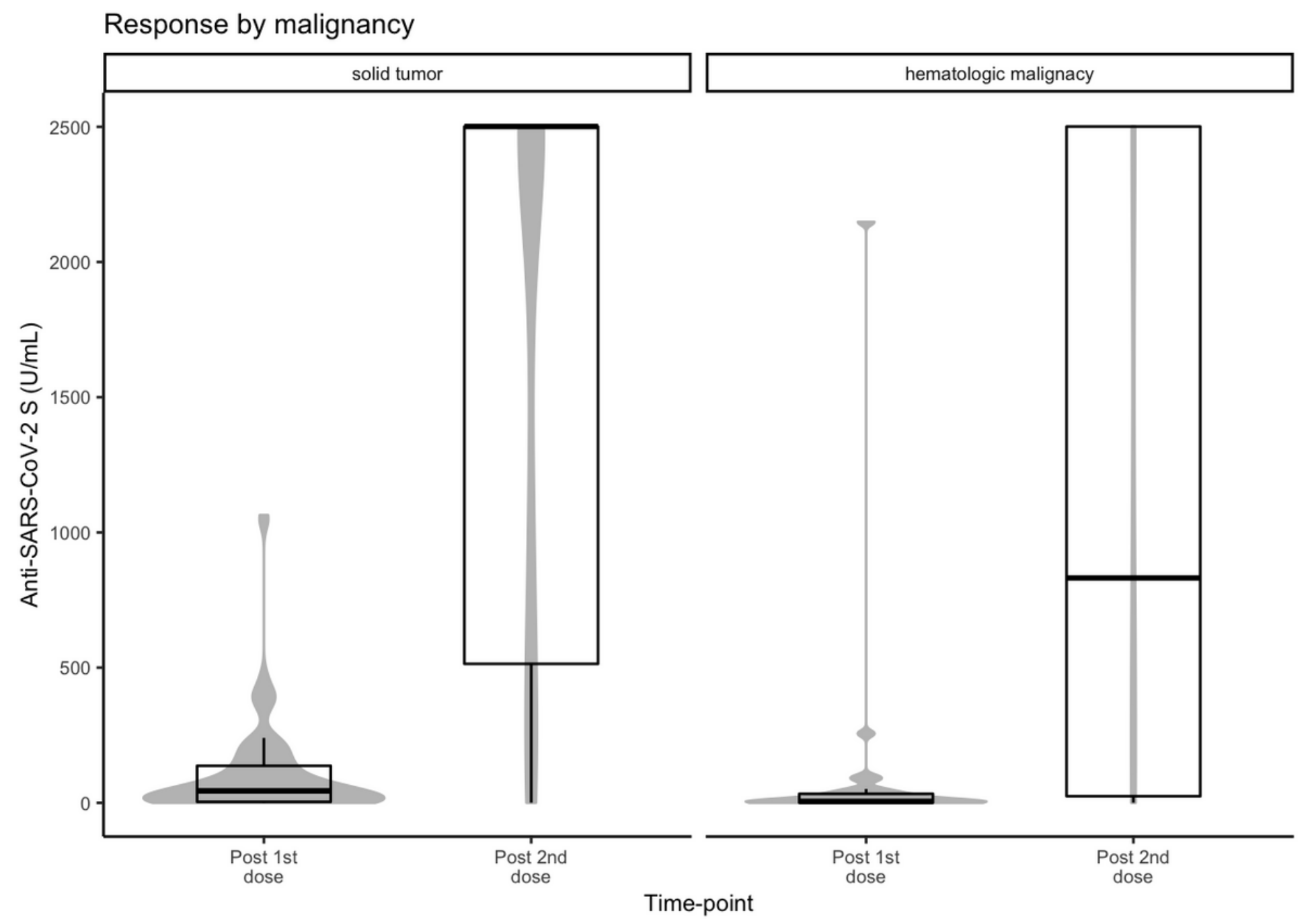

Figure 2

Anti-SARS-CoV-2 S IgG titers post 1 st dose and post 2 nd dose, stratified by solid and hematological malignancy 
Response by treatment

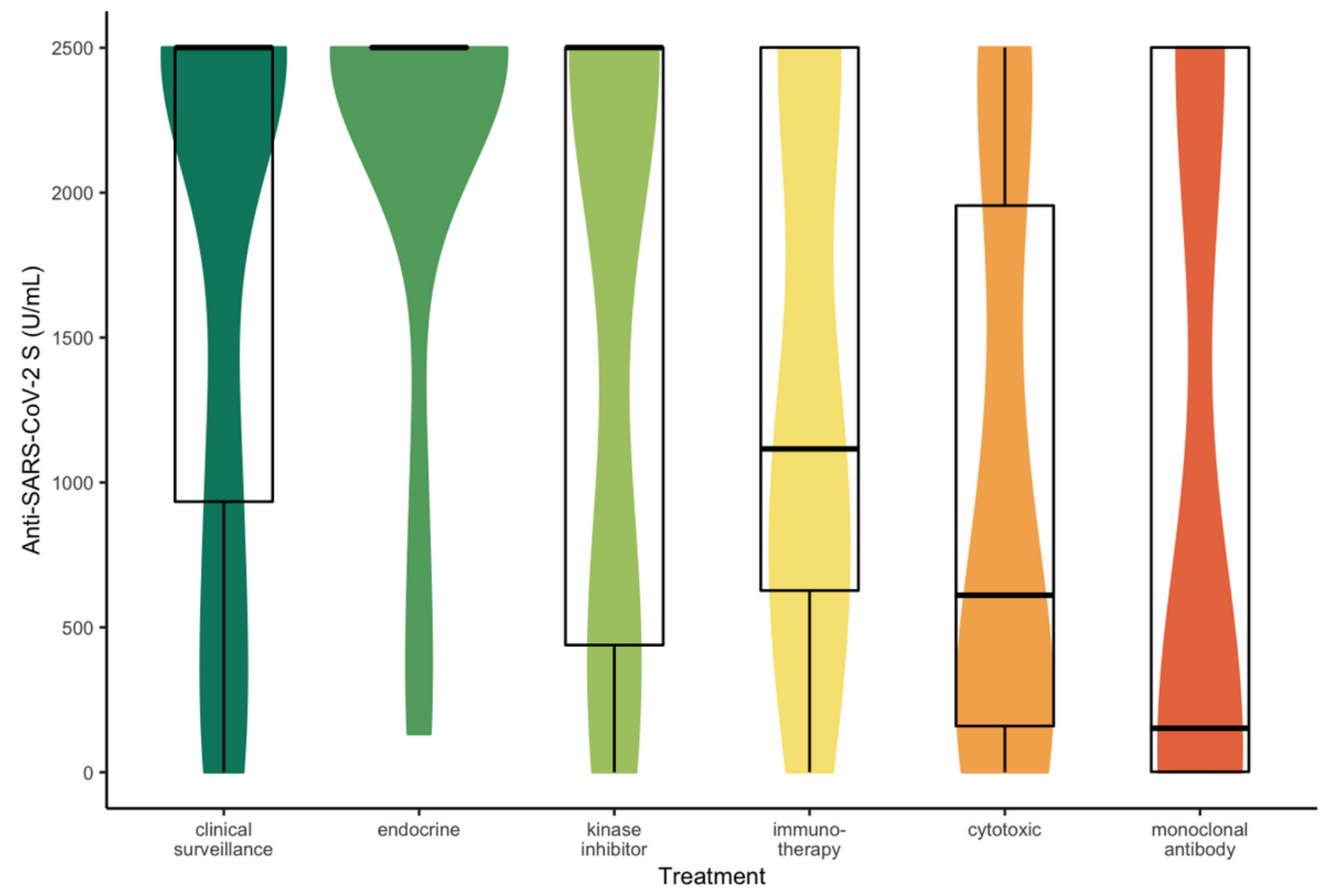

Figure 3

Frequency and Distribution of Anti-SARS-CoV-2 S IgG post 2nd dose, stratified by anti-cancer treatment modality

\section{Supplementary Files}

This is a list of supplementary files associated with this preprint. Click to download.

- floatimage4.png

- floatimage5.png 